\title{
The Impact of the Natural Lighting and Ventilation in Therapeutic Buildings: An Environmental Field Study in Makkah, Saudi Arabia
}

\author{
Alanoud Abdulaziz Alansari and Kazuhiro Hirao \\ Graduate School of Science and Engineering, Ritsumeikan University, Kusatsu, Shiga 525-8577, Japan
}

\begin{abstract}
Paradise Garden" concept has given rise to the application of several spiritual and aesthetic meaning that helped raise the efficiency of the therapeutic environment. The hypothesis revolves around the idea that the technological development increased the interest in the functional side rather than the aesthetic side in the current therapeutic buildings. This had a negative effect on the efficiency of the functional environment and thus exceeded the negative impact on the satisfaction and comfort of the building users. This hypothesis has been tested through two types of studies: first, analytical study of four hospitals by analyzing the horizontal projections to measure the effects of the natural lighting and ventilation; second, questionnaires were distributed to both the patients and the staff in the therapeutic buildings to measure the therapeutic environment efficiency and the extent of satisfaction of users of the building. It was concluded that the natural lighting and ventilation drive up healing rate in the therapeutic environment. The correctness of this idea is revealed by the conclusion that the technological advances in the medical field helped to raise the level of functional performance and thus it replaced a large part of the role of the natural lighting and ventilation.
\end{abstract}

Key words: Therapeutic buildings, paradise garden, Bimaristan.

\section{Introduction}

Muslims paid enough attention to health care and built hospitals (Bimaristan) which were provided with multiple services to meet the needs of patients. They developed Bimaristans and provided them with the necessary services in addition to the aesthetic meanings that were considered as a characteristic of Islamic architecture which made them as manifestation of challenge and beauty [1-4].

The development of therapeutic buildings increased until it reached its greatest stage in the Abbasid period (1029 1519), and this development in that time become manifestation of challenge and beauty [3].

The importance of the natural lighting and ventilation impact on the therapeutic environment was represented in the description of the Gardens of Paradise in the Quran; accordingly, the paradise

\footnotetext{
Corresponding author: Alanoud Abdulaziz Alansari, M.Sc., research field: architectural design. E-mail: alanoud.alansari@gmail.com.
}

principle is based on the simulation of paradise as described in the Quran. This principle is based on the interaction of the Muslim architect with the environment to fulfil the human life values in a manner that suits the lifestyle of a Muslim and follows the Islamic legislation $[5,6]$.

At the level of the development of medicine and science and the extent of keeping in line with other nations, another aspect of the therapeutic buildings has developed them. They were developed aesthetically and spiritually and this development contributed to the creation of therapeutic healthy environments that affect the body, spirit and mind of person to elevate him and help him to respond to healing. They were interested in simulating the Gardens of Paradise to provide the natural lighting and ventilation for the purpose of having the sensory and moral pleasures [6].

With the passage of time and the evolution of technology, the emphasis on the importance of the 
aesthetic meanings decreased. This reduced the focus on the therapeutic aspects inside the buildings. It negatively reduced the means which cause enjoyment for patients inside the building. There was a new approach that concentrated on the physical treatment and neglected the treatment of spirit and mind. This caused at the present time that the therapeutic buildings lack the spiritual aspects which embody the spiritual values derived from Islam [7].

\section{Methods}

To reach the findings, the researcher has relied on two types of field studies. First, he conducted a field study to monitor the current state of the existing therapeutic buildings in the study area. The researcher selected a random sample of four therapeutic buildings in different areas within the study spatial boundaries. He studied the extent to which the "paradise garden" concept was applied as to the natural lighting and ventilation of the buildings, This was verified through the study of the extent of the provision of adequate quantity of natural lighting, the use of modern building technologies, and the availability of natural ventilation in the interior spaces.

In the second part of the study, questionnaires were distributed to a random sample of the 125 therapeutic building users with the purpose of measuring the psychological effect of the building in its current state on the users whether they are patients or staff members. The questionnaire is closed and the answers are specified (Yes or No) and includes 2 paragraphs: first paragraph measures the direct contact with nature and consists of four questions [8]. As for the second paragraph, it measures overall rating of the building from the viewpoint of the persons participating in the study and consists of six questions. .

\section{Results}

In the first filed study:

- In three out of four buildings subject matter of the study, it reflects the awareness of natural light in the treatment areas;

- In three out of four buildings subject matter of the study, it reflects the focus on the main foyer and gives it a special importance in the designing aspect along with providing an abundance of natural light;

- In three out of four buildings subject matter of the study, internal or external gardens or both of them are provided as an awareness of its influence on the patients and curative environment.

In the second filed study:

- The buildings are directly adjacent to nature by $72 \%$ according to the current study;

- Healthcare buildings in the study area realize quality by $61.5 \%$ according to the current study.

\section{Discussions}

In the first filed study:

The design of Building No. (A) helps expose the patients to an abundance of light through the openings overlooking the internal gardens to support their feeling of serenity, thus promoting the recovery process (Fig. 1). It is also used the double height of ceiling in the foyer in order to make the patient and visitor feel warm welcome and hospitality and to diminish the fear and tension causing the worry to the patient during his visit to the hospital.

In Building No. (B), the presence of patients' inspection and control rooms are not exposed to any natural light or ventilation. Considering the ground, $1 \mathrm{st}$

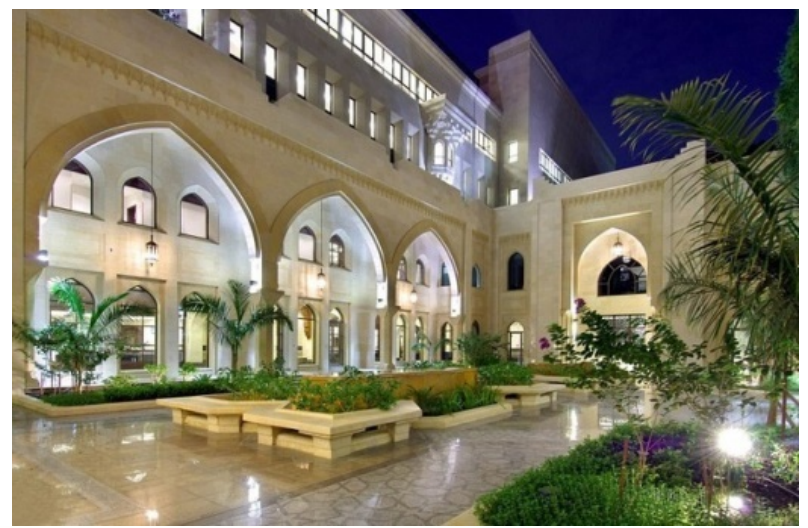

Fig. 1 The Building (A) internal gardens. 
and 2nd floors are vanished from the eastern and southern frontages as a result of the site topography. There is a number of staff offices locating at the eastern side of the first floor, which also means that they are not exposed to any amount of natural ventilation and light. On the other hand, the radiology rooms are installed in the west side of the same building. As a result of a number of the openings in the south frontage, the radiology rooms are isolated to be away of natural light, through a corridor separating between the frontage glass and radiology rooms (Fig. 2).

In Building No. (C), it is designed in a manner so that the foyer is built at height of full three floors along with providing a skylight and glass facade to allow as much as possible of introducing the natural light into the building (Fig. 3). These skylight openings

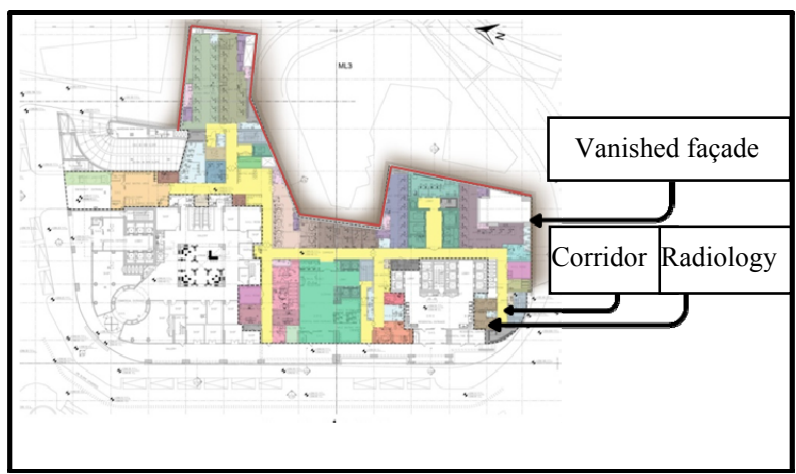

Fig. 2 Floor plan of Building (B).

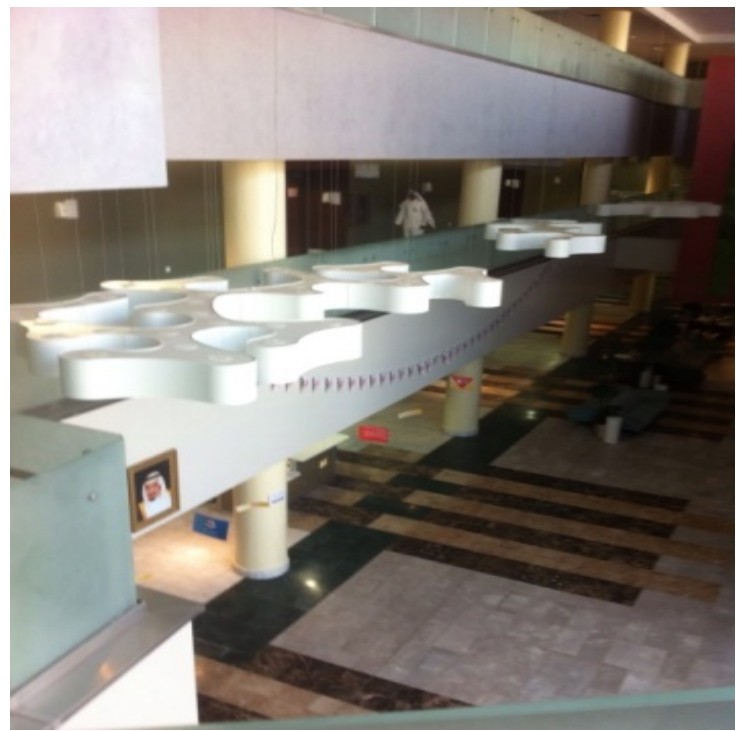

Fig. 3 The natural light in Building (C). are made to provide the depth of the building with the natural light. The places that are not exposed to the natural light are used to serve the functions of non-patient such as stores and staff's lounges and offices.

As for Building No. (D), it is divided into three sections connected by the corridors that are designed with large windows to allow introducing the natural light thereunto and all rooms overlook the natural landscape (Fig. 4). The building consists only of the ground floor, in view of the fact that the gym facility is located in the heart of the building, so its ceiling has been raised to be up of the level of the surrounding corridors and the openings are made to allow introducing the indirect natural light to gym hall (Fig. 5). The skylight is used in the foyer to provide as much as possible of introducing the natural light (Fig. 6). In the physical and occupational therapy rooms, the large glass windows are used to provide the

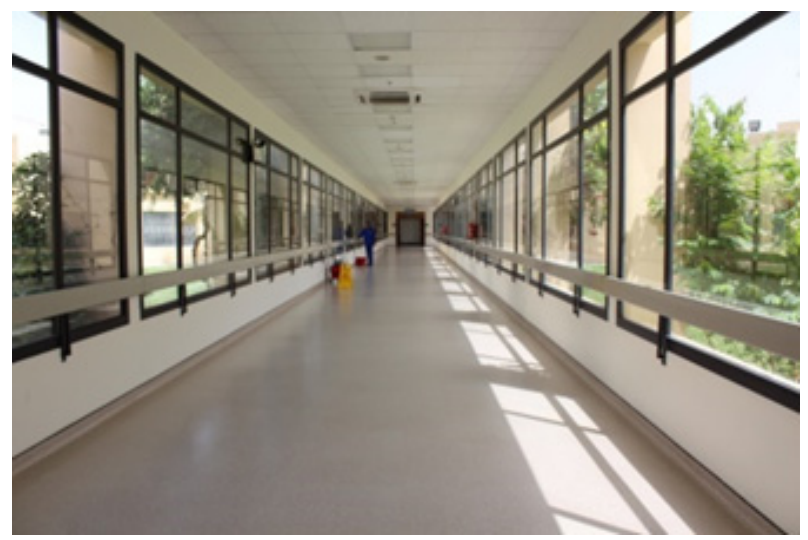

Fig. 4 Corridor's windows.

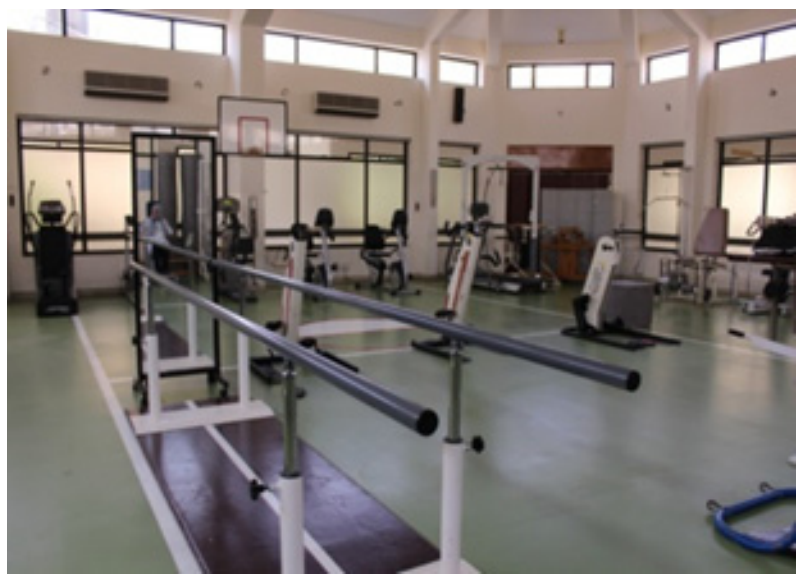

Fig. 5 Indirect natural light. 


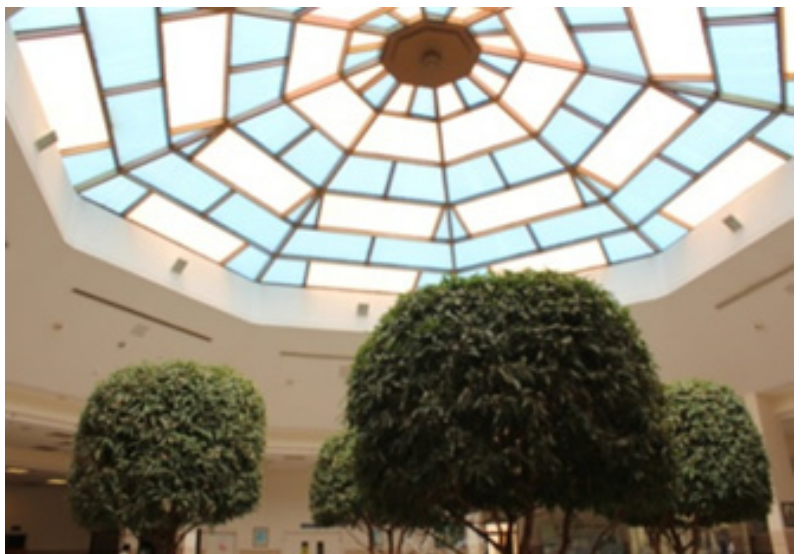

Fig. 6 The skylight.

Table 1 The first paragraph "yes" answer's percentage.

\begin{tabular}{ll}
\hline Phrase & Yes percentage \\
\hline Adequate natural light & $46.40 \%$ \\
Increase the size of windows & $93.60 \%$ \\
Isolation due to the industrial lighting & $78.40 \%$ \\
\hline
\end{tabular}

overlooking of gardens and benefiting from the sunlight.

In the second filed study:

For the first paragraph, as shown in Table 1, 46.4\% of the participating sample selected the "yes" answer concerning the building allowance of adequate natural light inside it. This was due to the different functions of the spaces that the participants occupied during their stay at the hospital and while participating in the study. For example, at one of the buildings where questionnaires were distributed, diagnosis rooms included windows while waiting rooms did not. $78.4 \%$ of the answers agreed that there were many spaces that to a large extent depend on artificial lighting; which gives a sense of isolation and closure.

In general, when asking whether healthcare buildings in the city need to increase the area of their windows, $93.6 \%$ of the sample answered "yes"; which indicates the stereotype that most of the participants have in their minds concerning isolating the external environment from the internal environment in healthcare buildings in the kingdom and this in turn may hamper or delay healing process.

In the second paragraph, which is concerned with studying the participants overall evaluation of the building,

In the first question, and depending on the results and opinions of the participants in the study, the area of the building was good enough for $92 \%$ of the sample that underwent the study selected the answer "good".

The overall shape of the building was also considered good for $70.4 \%$ of the sample chose the answer "good", but when limiting the question to the external facades, $90.4 \%$ of the participants selected the answer "bad" and as for the interior design of the hospital, most of the answers (69.6\%) were "bad" and $74.4 \%$ of the sample selected the answer "bad" concerning the quality of internal ventilation.

$95.2 \%$ of the sample answered that the overall environment in the healthcare building was good. When asking the participants about their opinion concerning furniture, the majority $(66.4 \%$ of the sample) chose the answer "bad". When comparing this percentage with the percentages in the answers concerning the interior design quality, the accordance between the two percentages proves largely; which illustrates that the interior of healthcare buildings in the study area in general does not provide adequate comfort for users.

As for the question about lighting in general, 62.4\% of the sample considered it as having good quality and $88 \%$ of the sample recognized the quality of artificial lighting while $89.6 \%$ of the sample answered "bad" concerning the quality of natural lighting.

In the second question of the same paragraph, $67.2 \%$ of sample replied that the building is generally good. When calculating the average percentage of the "good" answers in the first paragraph for all questions, the result was $51.4 \%$. There is naturally a difference between the two percentages as the first question considers building details while the second question considers the general look of the users, but the a proximity between the two percentages and average level of both of them somewhat shows the building quality level and its fulfillment of users' services. We 


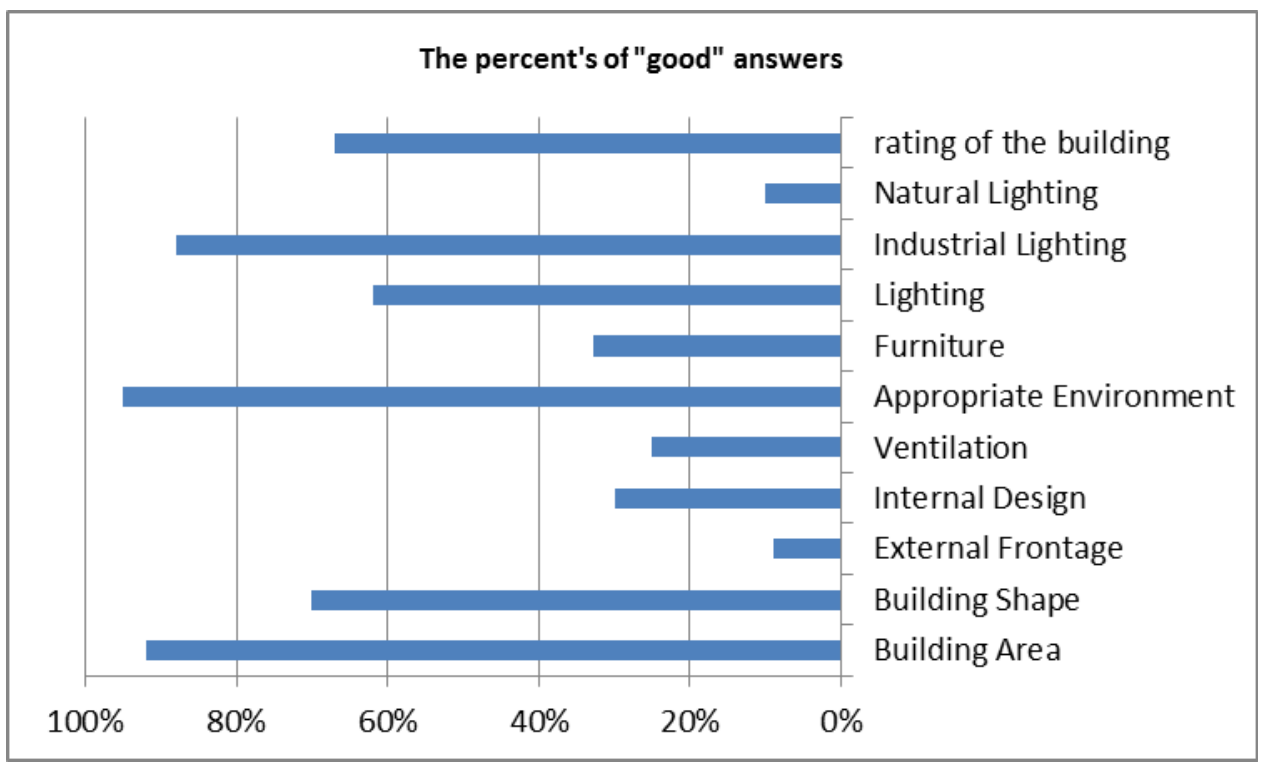

Fig. 7 The percent's of "good" answers.

can relatively reach the kinks by referring to the first question in the same paragraph. (Fig. 7)

\section{Conclusions}

We can draw the conclusions below:

- The designs of $75 \%$ of the buildings that underwent the first field study, specifically three buildings, reflected full awareness of the importance of adjacency with nature in therapeutic spaces. According to the second study, the buildings are adjacent to nature by $72 \%$;

- There is a considerable awareness of the importance of adjacency with nature in therapeutic environments in the study area;

- It is possible to have an appropriate environment that enhances healing process without taking fulfillment of the principles of building Bimaristans or Paradise Gardens in therapeutic buildings into account, but it is possible to link between lack of such principles and the weakness of the percentage of the building quality;

- The natural lighting and ventilation within the therapeutic buildings has a significant impact on users comfort and satisfaction, but it does not affect the efficiency of the functional aspect significantly for the absence of a lot of spiritual and aesthetic senses as recognized by the majority of the sample involved in the study, which did not adversely affect the quality of the therapeutic buildings, the services and functions established in them significantly according to the current study.

\section{References}

[1] Judy, M. H. 1997. Aethetics of Islamic Art. 1st ed. Amman: Dar Al-Safaa for Publishing and Distribution.

[2] Judy, M. H. 1419 AH. Arab Islamic ArchitectureInnovations \& Aesthetics. 1st ed. Amman: Dar Maysara for Publishing, Printing and Distribution.

[3] Eissa, A. 1401 AH. History of Bimaristans in Islam. Beirut: Al-Raed Al-Arabi Press.

[4] Mahdi, M. Z. 1983 AD. Landscaping in the Arab World. Libya: Al-Dar Al-Arabiyah Press.

[5] Al-Hathloul, S. B. A. 1414 AH. Arab-Islamic City: The Impact of Legislation on the Composition of Urban Environment. 1st ed. Riyadh: Al-Sahn Press.

[6] Hammad, M. 1401 AH. Thoughts about Islamic Architecture Based on the Quran and Sunnah. 1st ed. Riyadh: Al-Sahn Press.

[7] Khulousi, M. M. 1999. Hospitals and Health \& Social Centers. 1st ed. Beirut: Dar Qabes.

[8] Khalil, I. A.-D. 1401 AH. Nature in Western and Islamic Art. 2nd ed. Beirut: Al-Resalah Foundation. 